\title{
From embargo to control
}

A committee which has been striving for the past year to draft guidelines to control the use of a revolutionary, but currently embargoed, genetic engineering technique, last week paved the way for many uses of the technique to be resumed in the United States. Colin Norman reports from Washington

For nearly two years, many experiments involving the use of a newlydiscovered method of manipulating genes in living organisms have been under an embargo because of potential hazards associated with the research. But scientists in the United States who have been itching to use the technique may not have much longer to wait, for it now seems almost certain that the embargo will be lifted in the next few weeks and be replaced with controls designed to minimise the hazards.

The latest step in the tortuous process of developing those controls occurred last week when a committee of the National Institutes of Health (NIH) met to consider criticisms and proposed revisions of a set of detailed guidelines it drafted last December.

The committee stood solidly behind its work, resisting most suggestions that its draft guidelines should be made more restrictive, and it also gave its approval for one particular biological safety system to be used for some of the more hazardous genetic manipulation experiments.

The matter is now firmly in the hands of NIH Director Donald S. Fredrickson, who last week promised to issue a final set of guidelines within a month. Though Fredrickson will probably amend the draft guidelines, a statement he sent to the committee last week indicates that he has accepted the principles embodied in the draft and that any revisions he may make will be relatively minor.

The draft US guidelines seek to contain bacteria or viruses bearing transplanted genes by two methods. First, they spell out four levels of physical containment, ranging from the use of standard microbiological practice to the use of specially designed laboratories (such as biological warfare establishments) capable of handling the most virulent pathogens, and second, they specify that experiments with high potential risk should use viruses or bacteria genetically crippled so as to be virtually incapable of surviving outside the laboratory. The central, and most controversial, portion of the guidelines attempts to assign specific experiments to specific safety levels.
After the committee finally hammered out those guidelines at a meeting last December, Fredrickson sent them out to several scientists for review, and he also called a public meeting to solicit the views of outside groups. The result is a stack of comments more than a foot thick, on the basis of which Fredrickson last week suggested some specific revisions in the draft guidelines and asked the committee for its reactions.

Many of Fredrickson's suggestions simply removed inconsistencies in the draft, and were readily accepted by the committee. But in several instances where Fredrickson proposed changes which would have made the guidelines more restrictive, the committee demurred, arguing that its draft guidelines would provide ample protection against the potential hazards. Specifically, Fredrickson suggested that experiments involving the insertion into bacteria of uncharacterised genes from cold-blooded vertebrates should be placed in the same category as experiments with genes from higher animals (next to the highest level of physical containment, coupled with the use of crippled micro-organisms); he asked the committee to consider the suggestion that genes from other coldblooded animals and lower eukaryotes should only be transplanted into crippled bacteria; and he also asked the committee for its views on placing all genetic manipulation experiments with the monkey virus SV40 in the highest level of physical containment. Though the committee turned down all those suggestions, it remains to be seen whether Fredrickson will accept its views.

Whatever decisions Fredrickson makes on the fine details of the guidelines, it is clear that many genetic manipulation experiments will require the use of crippled viruses or bacteria before they are allowed to go ahead. In that regard, the committee last week took one important decision and came close to making a bad political blunder on a second.

At its meeting last December, the committee agreed that it should certify whether or not specific strains of viruses or bacteria have been sufficiently crippled to provide the degree of containment spelled out in the guidelines (it took on that assignment largely because no other competent national body is available). At last week's meeting, it was asked to certify two such crippled strains. If it approved them, the effect would be to give the green light to many experiments as soon as guidelines are published; if it turned them down, the embargo on experiments requiring crippled strains would effectively be maintained because no such strains would be available.

The first strain considered by the committee was a bacteriophage lambda, rendered incapable of surviving at body temperature and carrying three other genetic mutations which limit its infectivity and prevent it from surviving outside an artificial laboratory environment. Developed by Dr Philip Leder and his colleagues at NIH, details of the strain have already been published in Nature, and the committee members were provided with test data several weeks before their meeting. They certified the strain as being sufficiently weakened to provide an adequate biological safety barrier.

The second crippled micro-organism under consideration was a strain of the human gut bacterium E. coli, developed by Dr Roy Curtiss at the University of Alabama. Curtiss has been working on the strain for more than a year, and he has built a number of ingenious mutations into the organism to reduce its ability to survive outside the laboratory. $\mathrm{He}$ has also conducted exhaustive tests to measure the bacterium's chances of surviving. His test data were presented to the committee on the first day of the meeting in the form of a 147-page set of figures, graphs, tables and text. Though few members of the committee had the chance to go through Curtiss's data, they came close to voting on whether or not to approve the strain. Fortunately, however, it was decided-much to Curtiss's relief, it should be notedto defer a decision for a month to allow committee members to consider the data and confer with other experts.

Though many members of the committee have been keeping in close touch with Curtiss's experiments over the past year, and were therefore well versed in his overall results, if the committee had certified his strain on the basis of such a cursory examination of the data, it would have laid itself wide open to criticism. Biological containment, after all, is a central feature of the safety guidelines. Nevertheless, Curtiss's data is so extensive and by all accounts it provides such convincing evidence for the feebleness of his bacterial strain that the committee is very likely to approve the strain for use in genetic manipulation experiments.

Within the next few weeks, guidelines will thus be issued by NIH to govern that agency's support of genetic manipulation experiments, and the committee's certification of at least one crippled micro-organism has paved the way for a lifting of the embargo in the United States. 